\title{
PROBENECID INCREASES DOPAMINE METABOLITE 3,4-DIHYDROXYPHENYLACETIC ACID (DOPAC) IN RAT ADRENAL GLAND
}

\author{
Akio KAWAGUCHI*, Masami NIWA and Masayori OZAKI** \\ Department of Pharmacology 2, Nagasaki University School of Medicine. \\ Sakamoto-machi, Nagasaki 852. Japan
}

Accepted January 20, 1983

\begin{abstract}
Although norepinephrine and epinephrine are the predominant catecholamines (CAs) in peripheral tissues, peripheral dopamine (DA) systems are also physiologically significant. The DA is present both in the sympathetic ganglia and in the adrenal gland. We attempted to determine the possible presence of it in individual adrenal cells. We found increments in adrenal 3.4-dihydroxyphenylacetic acid (DOPAC) levels produced by probenecid, an inhibitor of anionic secretory mechanisms. Small amounts of DA and DOPAC were detected in the rat adrenal gland by using the high-performance liquid chromatographic electrochemical detection method. Two hr after probenecid treatment (200 $\mathrm{mg} / \mathrm{kg}$, i.p.), the concentration of striatal homovanillic acid approximately doubled compared with those of control rats, and the levels of striatal DOPAC remained much the same. Conversely, the adrenal DOPAC was markedly increased with no change in the levels of CAs. The existence of DOPAC and the increase of DOPAC by probenecid indicate that the adrenal DA may be independently granulated.
\end{abstract}

Nonstriatal dopaminergic systems are widely acknowledged. In peripheral sympathoadrenomedullary monoaminergic systems, sympathetic ganglia have small intensely fluorescent (SIF) cells (1). The neurotransmitter of these SIF celis is considered to be dopamine (DA) $(2,3)$. These SIF cells modify suppressively the transsynaptic neuronal transmission between precholinergic and post-noradrenergic neurons. (4).

A small amount of DA has been detected in the adrenal gland (5). Nevertheless, electron microscopic studies revealed that there were small granule chromaffin (SGC) cells (6), the third argentaffic cells in the

* Present address: Department of Surgery 1. Nagasaki University School of Medicine. Sakamoto-machi, Nagasaki 852, Japan.

* To whom reprint requests should be addressed. adrenal medulla. Whether or not adrenal DA is stored in the independent cells or merely exists as a precursor to norepinephrine (NE) has not been established.

The new and highly sensitive highperformance liquid chromatographic electrochemical method of assessing biogenic amines and their metabolites $(7,8)$ led to investigations of the dopaminergic mechanism in the adrenal gland.

We measured the accumulation of the DA metabolite 3.4-dihydroxyphenylacetic acid (DOPAC) after the treatment of probenecid, an inhibitor of acid transport processes (9) in the rat adrenal gland.

\section{Materials and Methods}

Animals: Male Wistar rats weighing 250$300 \mathrm{~g}$ were fed a standard diet (Funabashi Farm Co., Chiba, Japan) and water ad 
libitum and housed at $24^{\circ} \mathrm{C}$. These rats were given a $10 \%$ sucrose solution orally $24 \mathrm{hr}$ before decapitation since the cereal chow contained tyrosine and DOPA which modify the level of endogenous metabolites of biogenic amines (10).

The experimental group or control group were given probenecid (200 $\mathrm{mg} / \mathrm{kg}$, i.p.) or the vehicle alone, respectively. The rats were decapitated between 11:00 a.m. and 1:00 p.m., $2 \mathrm{hr}$ after administration of probenecid. The brain and adrenal glands were rapidly removed and the striatum was dissected on ice, as described by Glowinski and Iversen (11). All samples were rapidly frozen on dry ice and stored at $-25^{\circ} \mathrm{C}$.

Determination of amines and their metabolites: Within $48 \mathrm{hr}$ after decapitation, amines and metabolites were assayed using high-performance liquid chromatography (HPLC) with an electrochemical detector (ECD) and a modification of a previously reported method (7.8).

Tissue samples were homogenized in 4.0 $\mathrm{ml}$ of $0.4 \mathrm{M} \mathrm{HClO}$ containing $0.23 \mathrm{mM}$ ascorbic acid as an antioxidant and 3,4dihydroxybenzylamine (DHB) as an internal standard for catecholamines (CAs). The homogenates were centrifuged at 15.000 r.p.m. for $15 \mathrm{~min}$ at $2^{\circ} \mathrm{C}$.

DOPAC and HVA were extracted from a $3.0 \mathrm{ml}$ aliquot of the supernatant by the method of Karasawa et al. (12). Briefly, the supernatant was passed through a Sephadex G-10 column $(1.0 \mathrm{~cm}$ i.d. $\times 3.0 \mathrm{~cm})$. The column was washed with $3.0 \mathrm{ml}$ of $0.01 \mathrm{M}$ $\mathrm{HCl}$, and then DOPAC and HVA were extracted with $18 \mathrm{ml}$ of $0.01 \mathrm{M} \mathrm{HCl}$. The eluate was transferred to the OAE Sephadex A-25 (AcO- form) column $(0.5 \mathrm{~cm}$ i.d. $\times 6.4$ $\mathrm{cm}$ ). After washing with $6.0 \mathrm{ml}$ of $0.02 \mathrm{M}$ $\mathrm{CH}_{3} \mathrm{COOH}$ and $0.5 \mathrm{ml}$ of $0.2 \mathrm{M} \mathrm{NaCl}$, DOPAC and HVA were eluated with $3.0 \mathrm{ml}$ of $0.2 \mathrm{M} \mathrm{NaCl}$ and then assayed simultaneously by HPLC-ECD. The chromato- graph (6000 A pump, U6K universe injector, Waters Assoc., MA., U.S.A.) was equipped with a glassy carbon amperometric detector (+0.70V. LC-4A. Bioanalytical Systems, I.N. U.S.A) and a $0.39 \mathrm{~cm}$ i.d. $\times 30 \mathrm{~cm}$ reverse phase $\mathrm{C}_{18}$ ( $\mu$-Bondapak $\mathrm{C}_{18}$. Waters Assoc.) column. The mobile phase, $0.15 \mathrm{M}$ monochloroacetate buffer, pH 3.0, containing $2 \mathrm{mM}$ $\mathrm{Na}_{2}$ EDTA and $9 \%$ methanol was pumped at a rate of $1.5 \mathrm{ml} / \mathrm{min}$.

The other $1.0 \mathrm{ml}$ aliquot of the supernatant containing the CAs was adjusted to $\mathrm{pH} 8.6$ by the addition of $2.0 \mathrm{ml}$ of $3 \mathrm{M}$ tris- $\mathrm{HCl}$ buffer, $\mathrm{pH} 8.6$, and transferred to a $5.0 \mathrm{mi}$ conical reaction vial containing $100 \mathrm{mg}$ of acid washed alumina. The CAs were adsorbed onto the alumina by vortexing for $5 \mathrm{~min}$. After washing with distilled water, the CAs were eluted by the addition of $0.5 \mathrm{ml}$ of $0.1 \mathrm{M} \mathrm{HClO}_{4}$. The mobile phase of $\mathrm{HPLC}$. $0.15 \mathrm{M}$ monochloroacetate buffer, pH 3.0. containing $0.12 \mathrm{mM}$ sodium octyl sulfate was pumped at a rate of $1.2 \mathrm{ml} / \mathrm{min}$. All other chromatographic conditions were identical to those described above. The NE, epinephrine (E), DHB and DA eluted from the column with retention times of $4.5,6.1$, 7.5 and $10.5 \mathrm{~min}$, respectively.

Drugs: Probenecid was dissolved in a minimal volume of $1 \mathrm{M} \mathrm{NaOH}$, some saline $(0.9 \% \mathrm{~W} / \mathrm{V})$ added and $\mathrm{pH}$ adjusted with $2 \mathrm{M}$ $\mathrm{HCl}$ to 8.6. The solution was diluted with saline in a concentration of $20 \mathrm{mg} / \mathrm{ml}$. Probenecid was a gift from the Nippon Merck Banyu Co. (Tokyo, Japan). DHB HBr was obtained from the Aldrich Chemical Co., WI. U.S.A. NE bitartrate, $E$ bitartrate, DA $\mathrm{HCl}_{\text {r }}$ DOPAC, homovanillic acid (HVA) were purchased from the Sigma Chemical Co., MO, U.S.A.

Others: Protein concentration of the tissue pellets was determined by the method of Lowry et al. (13).

Values are expressed as the average \pm S.E. The statistical significance of differences 
between mean values was analyzed using the Student's $t$-test.

\section{Results}

In the rat adrenal, the amount of DA is only $1.4 \%$ of all adrenal CAs. The amount of NE was $26.4 \%$ and that of $E$ was $72.2 \%$. Although the percentage of DA is minute, the value when expressed as $\mathrm{ng} / \mathrm{mg}$ protein was similar to that in the striatum which is richly innervated with dopaminergic nerve endings (The adrenal gland, $63 \pm 7 \mathrm{ng} / \mathrm{mg}$ protein and the striatum. $74 \pm 3 \mathrm{ng} / \mathrm{mg}$ protein). No changes were observed in CAs levels $2 \mathrm{hr}$ after probenecid treatment (Table 1).

Figure 1 shows typical HPLC profiles of DA metabolites extracted from the rat adrenal gland (cited in the upper half of the figure) and the striatum (in the lower half). The DOPAC and HVA eluted from the HPLC column with retention times of 8.4 and 21.6 min, respectively.

The effects of probenecid (200 $\mathrm{mg} / \mathrm{kg}$, i.p.) on the concentrations of DOPAC and HVA in the rat adrenal gland and striatum are illustrated in Table 2. Whereas the concentration of striatal HVA increased by $156 \%$ and that of DOPAC by $35 \%$, the adrenal DOPAC markedly increased (159\%). We could not detect adrenal HVA. When we calculated the ratio of DOPAC to DA, no significant changes in the ratio were detected
Probenecid

$(-)$

$(+)$
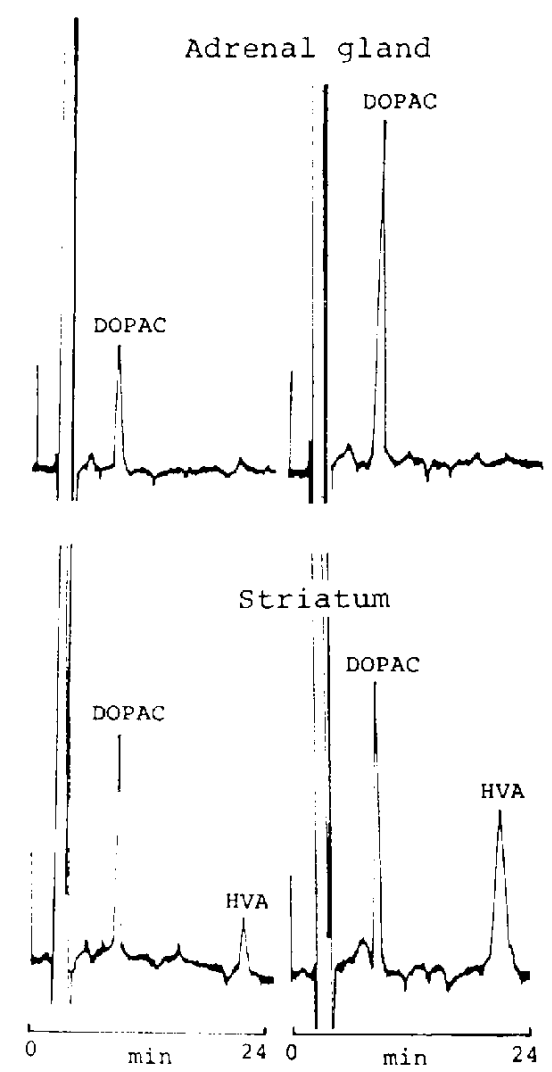

Fig. 1. Typical chromatograms of tissue DOPAC and HVA extracted as described in "Materials and Methods" from a rat adrenal gland (in the upper half) and a rat striatum (in the lower half). The left and the right sides are the chromatogram from a control rat and a probenecid (200 $\mathrm{mg} / \mathrm{kg}$, i.p., $2 \mathrm{hr}$ after)-treated rat, respectively.

Table 1. Change of catecholamines contents in adrenal gland and striatum $2 \mathrm{hr}$ after probenecid administration

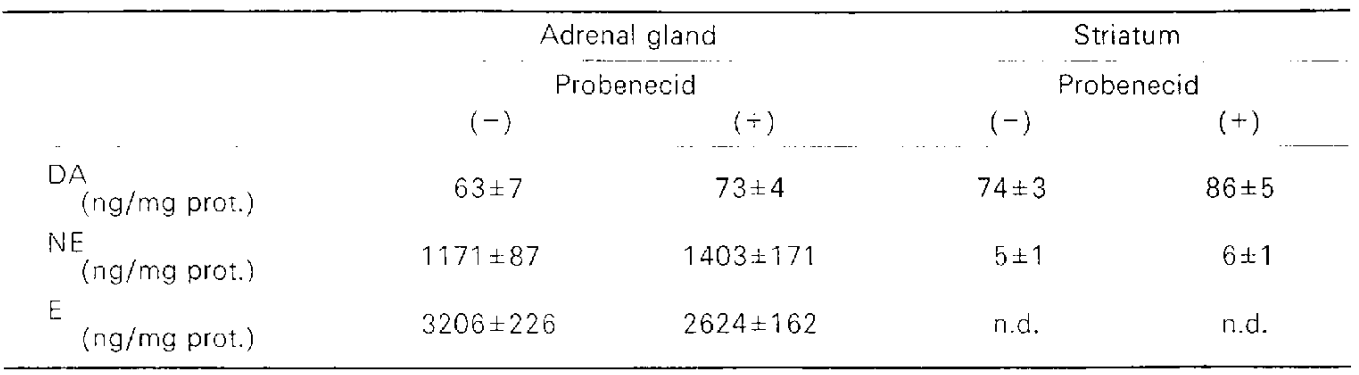

Rats were given probenecid (200 $\mathrm{mg} / \mathrm{kg}$, i.p.). DA: dopamine, NE: norepinephrine, E: epinephrine. n.d.: non-detectable. Each value is the average \pm S.E. of 5 determinations. 
Table 2. Accumulation of metabolites of dopamine 2 hr after probenecid administration

\begin{tabular}{|c|c|c|c|c|}
\hline \multirow[b]{2}{*}{$-\ldots$} & \multicolumn{2}{|c|}{$\begin{array}{l}\text { Adrenal gland } \\
\text { Probenecid }\end{array}$} & $\mathrm{P}$ & sid \\
\hline & $(-)$ & $(t)$ & $(-)$ & $(+)$ \\
\hline $\begin{array}{l}\text { DOPAC } \\
\text { (ng/mg prot.) }\end{array}$ & $2.7 \pm 0.4$ & $7.0 \pm 0.5^{* *}$ & $9.7 \pm 0.6$ & $13.1 \pm 0.9^{*}$ \\
\hline $\begin{array}{l}\text { HVA } \\
\text { (ng/mg prot.) }\end{array}$ & n.d. & n.d. & $6.2 \pm 0.5$ & $15.9 \pm 1.4^{* *}$ \\
\hline
\end{tabular}

Rats were given proberiecid (200 $\mathrm{mg} / \mathrm{kg}$, i.p.). DOPAC: 3,4-dihydroxyphenylacetic acid. HVA: homovanillic acid. n.d.: non detectable. Each value is the average $\pm S$.E. of 5 dotcrminations. $* P<0.05$. **P<0.001 with respect to the control value.

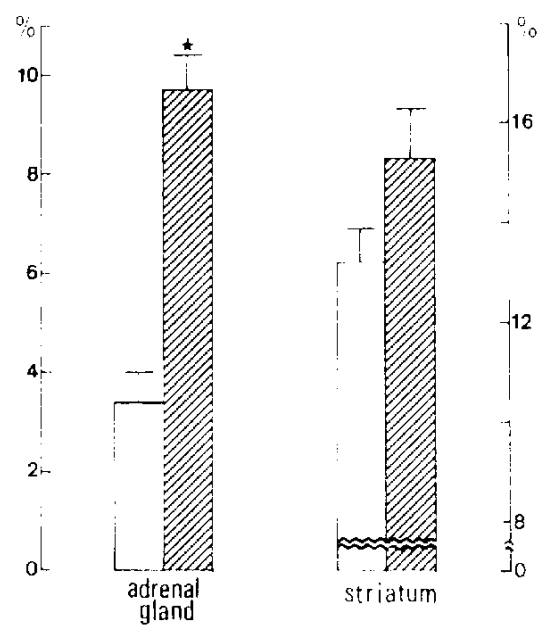

Fig. 2. Effect of probenecid (200 mg/kg, i.p., $2 \mathrm{nr}$ after) treatment on the DOPAC/DA ratio in the rat adrenal gland and the rat striatum. Tho shaded columns denote the data from probenecid-treated rats and the open columns, the data from control rats. Results are the average \pm S.E. of data obtained with groups of 5 animals. $₫ P<0.001$ with respect to the control value.

in the striatum (Fig. 2). In addition, the adrenal DOPAC/DA ratio is smaller than the striatal ratio (the average values in the control rats: in the adrenal gland, $3.4 \%$ and in the striatum, 13.2\%).

\section{Discussion}

In the course of our investigations, we attempted to measure traces of biogenic amines in various organs and tissues, the objective being to determine whether or not adrenal DA could be functional in the sympathoadrenomedullary system since our sensitive and quantitative method of biogenic amines made feasible estimations of minute amounts of adrenal DA $(14,15)$. Additionally, we have found that DA was released into the blood stream of the adrenal vein in response to hypotension following hemorrhage. We observed that the time course of adrenal DA release differed from that of $E$ and NE (16). The present study was designed to determine the mode of existence of adrenal DA as compared with levels in the striatum which is innervated with dopaminergic nerve endings originating from substantia nigra nuclei (17). For our purposes, we used probenecid, an inhibitor of the acid transport mechanism in the brain $(9,18)$.

Probenecid produced a marked elevation of DOPAC in the adrenal gland. while the levels of DOPAC in the striatum were little affected. The HVA in the striatum was markedly increased. This effect of probenecid on the striatum is largely consistent with findings of other workers $(19,20)$. Why probenecid mainly increases HVA but not DOPAC can be explained as follows: in the brain, DOPAC is formed from DA released into the synaptic cleft mainly by intraneuronal monoamine oxidase and is a precursor of HVA. Actually. Westerink and Spaan (21) calculated that $80 \%$ of the HVA is formed from DOPAC. Since there is no substantial 
catechol-0-methyltransferase activity in dopaminergic nerve terminals (22) and DOPAC is probably formed in dopaminergic nerve endings $(21,23)$, without the transport of DOPAC to extraneuronal regions, DOPAC might not be catabolized to HVA. Thus it was considered that probenecid cannot block this transport mechanism or that DOPAC is transported out of the brain by a probenecid insensitive transport mechanism.

The adrenal DOPAC was markedly elevated by probenecid. This is surprising in view of the findings in the case of the striatum. The acid metabolites produced in the adrenal gland may be extruded by a different mechanism in the case of the brain. The existence of adrenal DOPAC and the increment of DOPAC by probenecid lead us to suggest that adrenal DA is granulated independently and released to the outside of cells containing DA granules as DOPAC is formed from the released and reuptaken DA. This is partly supported by the previous findings of dopaminergic SIF cells in the sympathetic ganglion (24).

Van Wijk et al. found that probenecid acted not only as an inhibitor of the acid transport mechanism in the choroid plexus, but it also stimulated serotonin synthesis in the serotonergic neurons of the rat brain (25). Although there is no documented evidence that probenecid stimulates the CAs synthetizing system, such an effect would contribute to elevation of the adrenal DOPAC levels.

The level of DA in the adrenal gland was $1.4 \%$ that of all CAs, this value being somewhat low when compared with findings in a morphological study of SGC in the mouse adrenal gland. Kobayashi and Coupland (6) calculated that the SGC cells accounted for $4 \%$ of all argentaffic chromaffin cells. There is a species difference or SGC cells containing other monoamines may exist in addition to dopaminergic SGC cells. The possibility of the latter may be supported by the recent immunohistofluorescence findings of serotonergic SIF cells in the sympathetic ganglion (26), and a biochemical study showed that serotonin was granulated in the adrenal gland (27).

The HVA in the adrenal gland could not be detected using our method, and the ratio of DOPAC to DA of the adrenal gland was much smaller than findings in the case of the striatum. In the rat brain, levels of DOPAC are comparable to those of HVA (28). This discrepancy may be derived from the different turnover rates and/or the degradation processes of DA. However, until data have been obtained with regard to the effect of various drugs which act on dopaminergic systems. the explanation presented remains only speculative.

Since DA was detected in the peripheral adrenergically-innervated tissue of the rat (29) and we did not measure DA and DOPAC in the adrenal cortex and medulla separately, the possibility that the sympathetic postganglionic nerves system of the adrenal cortex is dopaminergically innervated cannot be entirely excluded.

Acknowledgements: We thank K. Kunisada for technical help and $M$. Ohara for advice on the manuscript.

\section{References}

1) Williams, T.H.: Electron microscopic evidence for an autonomic interneuron. Nature 214, 309-310 (1965)

2) Bjorklund, A., Cegrell, L., Falck, B., Ritzen, M. and Rosengren, E.: Dopamine containing cells in sympathetic ganglia. Acta Physiol. Scand. 78, 334-338 (1970)

3) Bjorklund, A., Ehinger, B. and Falck, B.: A method for differentiating dopamine from noradrenaline in tissue section by microspectrofluorimetry. J. Histochem. Cytochem. 16, 263$270(1968)$

4) Libet, B.: Functional roles of SIF cells in slow synaptic actions. In Histochemistry and Cell Biology of Autonomic Neurons, SIF cells, and Paraneurons, Edited by Eränkö, O., Soinila, S. 
and Päivärinta, H., Advances in Biochemical Pyschopharmacology. Vol. 25, p. 111-118. Raven Press, New York (1980)

5) Stjarne, L.: The synthesis, uptake and storage of catecholamines in the adrenal medulla. in Catecholamines, Handbook of Exp. Pharmacol. New Series XXXIII, Edited by Blasko, $H$. and Musholl, E., p. 231-269, Springer, Berlin, Heidelberg and New York (1972)

6) Kobayashi, S. and Coupland, R.E.: Two populations of microvesicles in the SGC (small Granule Chromaffin) cells of the mouse adrenal medulia. Arch. Histol. Japon. 40, 251-259 (1977)

7) Hefti, F.: A simple, sensitive method for measuring 3.4-dihydroxyphenylacetic acid and homovanillic acid in rat brain tissue using highperformance liquid chromatography with electrochemical detection. Life Sci. 25, 775782 (1979)

8) Felice. L.J., Felice, J.D. and Kissinger, P.T.: Determination of catecholamines in rat brain parts by reverse-phase ion-pair liquid chromatography. J. Neurochem. 31, 1461-1465 (1978)

9) Spector, R. and Lorenzo, A.V.: The effects of salicylate and probenecid on the cerebrospinal fluid transport of penicilin, aminosalicylic acid and iodide. J. Pharmacol. Exp. Ther. 188, 55-65 (1974)

10) Heffner, T.G., Hartman, J.A. and Seiden, L.S.: Foeding increases dopamine metabolism in the rat brain. Science 208, 1168-1170 (1980)

11) Glowinski, J. and Iversen, L.L.: Regional studies of catccholamines in the rat brain. I. The distribution of $[3 \mathrm{H}]$ norepinephrine, [3H] dopamine and $\left[{ }^{3} \mathrm{H}\right]$ DOPA in various regions of the brain. J. Neurochem. 13, 655-669 (1966)

12) Karasawa, T., Nakamura, 1. and Shimizu, M.: Simultaneous microdetermination of homovanitlic acid and 5-hydroxyindoleacetic acid in brain tissue using Sephadex G-10 and OAE Sephadex A-25. Life Sci. 15, 1465-1474 (1974)

13) Lowry, O.H., Rosebrough, N.J., Farr, A.L. and Randall, R.J.: Protein measuremont with the Folin phenol reagent. J. Biol. Chem. 193, 265$275(1951)$

14) Maemura, S., Niwa, M. and Ozaki, M.: Characteristic alterations in adrenal catecholamine contents in SHR. SHRSP and WKY during development of hypertension and stroke. Japan. Heart J. 23, 593-602 (1982)

15) Kawano, T., Niwa, M., Fujita, Y., Ozaki, M. and Mori, K.: An improved method for analysis of catecholamines-gas-liquid chromatography (GLC) equipped with an electron-capture detector. Japan. J. Pharmacol. 28, 168-171 (1978)

16) Ohmiya, T., Shibata, O., Maemura, S., Niwa, M., Ozaki, M., Osoegawa, Y., Aritome, Y. and Tsuchiya, R.: Dopamine secretion from the adrenal medulla during hypotension induced by hemorrhage in dogs. Folia Pharmacol. Japon. 79, 77-84 (1982) (Abs, in English)

17) Fuxe, K.: Evidence for the existence of monoamine neurons in the central nervous system. IV. Distribution of monoamine nerve terminals in the central nervous system. Acta Physiol. Scand. 64, Supp. 247, 39-85 (1965)

18) Van der Poel, F.W., Van Praag, H.M. and Korf, J.: Eviderice for a probenecid-sensitive transport system of acid monoamine metabolites from spinal subarachnoid space. Psychopharmacology (Berlin) 52, 35-40 (1977)

19) Wilk, S., Watson, E. and Travis, B.: Evaluation of dopamine metabolism in rat striatum by a gas chromatographic technique. Eur. J. Pharmacol. 30, 238-243(1975)

20) Guldberg, H.C. and Broch, O.J.: On the mode of action of reserpine on dopamine metabolism in the rat striatum. Eur. J. Pharmacol. 13, 155-167 (1971)

21) Westerink, B.H.C. and Spaan, S.J.: Estimation of the turnover of 3-methoxytyramine in the rat striatum by HPLC with electrochemical detection: Implications of the sequence in the cerebral metabolism of dopamine. J. Neurochem. 38, 342-347 (1982)

22) Kaplan, G.P., Hartman, B.K. and Crevelling. C.R.: Immunohistochemical demonstration of catechol-O-methyltransferase in mammalian brain. Brain Res. 167, 241-250 (1979)

23) Roffler-Tarlov, S., Sharman, D.F. and Tegerdine, P.: 3.4-Dihydroxyphenvlacetic acid and 4hydroxy-3-methoxyphenylacetic acid in mouse striatum: A reflection of intra and extraneuronal metabolism of dopamine? Br. J. Pharmacol. 42, 343-351 (1971)

24) Karoum, F., Garrison, C.K., Neff, N. and Wyatt, R.J.: Trans-synaptic modulation of dopamine metabolism in the rat superior cervical ganglion. J. Pharmacol. Exp. Ther. 201, 654-661 (1977)

25) Van Wijk, M., Sebens, J.B. and Korf, J.: Probenecid-induced increase of 5-hydroxytryptamine synthesis in rat brain, as measured by formation of 5-hydroxytryptophan. Psychopharmacology (Berlin) 60, 229-235 (1979)

26) Verhofstad, A.A.J.. Steinbusch, H.W.M., Penke, B., Varga, J. and Joosten, H.W.J.: Serotonin-immunoreactive cells in the superior cervical ganglion of the rat. Evidence for the existence of separate serotonin- and catechol- 
amine-containing small ganglionic cells. Brain Res. 212, 39-49 (1981)

27) Snyder, S.H., Axelrod, J. and Zweig, M.: A sensitive and specific fluorescence assay for tissue serotonin. Biochem. Pharmacol. 14, 831835 (1965)

28) Westerink, B.H.C. and Korf, J.: Rapid concurrent automated fluorimetric assay of noradrenaline, dopamine. 3,4-dihydroxyphenyl- acetic acid, homovanillic acid and 3-methoxytyramine in milligram amounts of nervous tissue after isolation on Sephadex G 10. J. Neurochem. 29, 697-706 (1977)

29) Bell, C, and Gillespie, J.S.: Dopamine and noradrenaline levels in peripheral tissues of several mammalian species. J. Neurochem. 36 , $703-706(1981)$ 